\title{
Dry Reforming of Methane over a Ruthenium/Carbon Nanotube Catalyst
}

\author{
Yuan Zhu ${ }^{1}$, Kun Chen ${ }^{2}$, Robert Barat ${ }^{1, *}$ and Somenath Mitra ${ }^{2, *(10}$ \\ 1 Otto H. York Department of Chemical and Materials Engineering, New Jersey Institute of Technology, \\ Newark, NJ 07102, USA; yz348@njit.edu \\ 2 Department of Chemistry and Environmental Science, New Jersey Institute of Technology, \\ Newark, NJ 07102, USA; kc226@njit.edu \\ * Correspondence: robert.b.barat@njit.edu (R.B.); somenath.mitra@njit.edu (S.M.)
}

Received: 23 January 2020; Accepted: 4 March 2020; Published: 9 March 2020

\begin{abstract}
In this study, $\mathrm{CH}_{4}$ dry reforming was demonstrated on a novel microwave-synthesized ruthenium $(\mathrm{Ru}) /$ carbon nanotube $(\mathrm{CNT})$ catalyst. The catalyst was tested in an isothermal laboratory-packed bed reactor, with gas analysis by gas chromatography/thermal conductivity detection. The catalyst demonstrated excellent dry-reforming activity at modest temperatures $(773-973 \mathrm{~K})$ and pressure $\left(3.03 \times 10^{5} \mathrm{~Pa}\right)$. Higher reaction temperatures favored increased conversion of $\mathrm{CH}_{4}$ and $\mathrm{CO}_{2}$, and increased $\mathrm{H}_{2} / \mathrm{CO}$ product ratios. Slight coke deposition, estimated by carbon balance, was observed at higher temperatures and higher feed $\mathrm{CH}_{4} / \mathrm{CO}_{2}$. A robust global kinetic model composed of three reversible reactions-dry reforming, reverse water gas shift, and $\mathrm{CH}_{4}$ decomposition-simulates observed outlet species concentrations and reactant conversions using this $\mathrm{Ru} / \mathrm{CNT}$ catalyst over the temperature range of this study. This engineering kinetic model for the $\mathrm{Ru} / \mathrm{CNT}$ catalyst predicts a somewhat higher selectivity and yield for $\mathrm{H}_{2}$, and less for $\mathrm{CO}$, in comparison to previously published results for a similarly prepared $\mathrm{Pt} \_\mathrm{Pd} / \mathrm{CNT}$ catalyst from our group.
\end{abstract}

Keywords: catalysis; ruthenium; reforming; carbon nanotubes; methane; carbon dioxide

\section{Introduction}

Because of enhanced petroleum production by hydraulic fracturing, vast quantities of co-produced natural gas are flared annually worldwide [1,2]. In Texas, for example, a lack of sufficient gas pipeline capacity has severely depressed local natural gas market prices, resulting in negative prices and more flaring [3]. In addition to flaring, there is also concern for fugitive $\mathrm{CH}_{4}$ emissions associated with petroleum production [4]. Methane has a global warming potential 30 times higher than $\mathrm{CO}_{2}$ [5].

Methane dry reforming (DR) (overall: $\mathrm{CH}_{4}+\mathrm{CO}_{2} \rightarrow 2 \mathrm{CO}+2 \mathrm{H}_{2}, \Delta \mathrm{H}_{298 \mathrm{~K}}=2.473 \times 10^{5} \mathrm{~J}$ ) would remove two greenhouse gases while generating useful synthesis gas $\left(\mathrm{H}_{2}, \mathrm{CO}\right)$ as a chemical feedstock [6-8], especially for important chemicals such as ammonia and methanol, and for Fischer-Tropsch liquids $[9,10]$. The energy needed for the reforming can be supplied by burning some of the $\mathrm{CH}_{4}$. The $\mathrm{CO}_{2}$ can be trucked in, especially from sequestration sources. While this scheme does not ultimately eliminate the greenhouse gases, it does provide some useful return in the form of fuels and/or chemicals. Alternatively, the DR could be solar powered [11].

Typical heterogeneous DR catalysts use inorganic oxide supports; e.g., $\mathrm{Al}_{2} \mathrm{O}_{3}, \mathrm{SiO}_{2}, \mathrm{TiO}_{2}$ [6,12-14]. The active sites fall into two groups. First are base-metals, including $\mathrm{Fe}, \mathrm{Co}$, and $\mathrm{Ni}[6,12,13]$. The $\mathrm{Ni}$ is widely studied since it is catalytically active and cheap. However, the Ni catalyst sinters at common DR reaction temperatures $(800-1100 \mathrm{~K})$, and has a relatively weak coking resistance $[6,13]$. Cobalt offers an improved coking resistance compared to Ni [15]. In a recent development [16], a highly 
stable and coke-resistant catalyst composed of Mo-doped Ni nanoparticles on a MgO support was demonstrated for high DR activity.

The second active site group consists of noble metals, commonly $\mathrm{Rh}, \mathrm{Ru}, \mathrm{Pt}, \mathrm{Pd}$, and Ir $[6,14,17]$. Although expensive, noble metal catalysts resist coking, sinter less, and are more active for higher-temperature applications.

A potentially useful support for DR catalysts is carbon nanotubes (CNTs). The CNTs are one-dimensional cylindrical structures consisting of wrapped single or multi-layer graphene sheets [18]. Its special structure results in excellent thermal and electrical conductivities, high mechanical strength, large surface area, relatively high oxidation stability, surface chemical flexibility and porous structure [19].

The advantages of CNTs as catalyst supports for a number of heterogeneous catalysis processes have been identified. Dry reforming of $\mathrm{CH}_{4}$ over $\mathrm{Ni} / \mathrm{CNT}$ and $\mathrm{Ni} / \mathrm{SiO}_{2}$ catalysts produced approximately the same conversions, but Ni/CNT showed much better stability. This was attributed to a redirection of carbon deposits away from the Ni sites to growth along the CNT tips [20]. Dry reforming of $\mathrm{CH}_{4}$ over $\mathrm{Co} / \mathrm{CNT}$ and $\mathrm{Co} / \mathrm{MgO}$ showed higher $\mathrm{CH}_{4}$ conversions from $\mathrm{Co} / \mathrm{CNT}$, which also had lower carbon deposition rates and less catalyst deactivation [21].

In this work, Ru supported on a CNT catalyst was synthesized by a versatile microwave technique, and then tested for methane DR activity. There is no current literature on the use of $\mathrm{Ru}$ (as the sole metal) on CNT used as DR catalyst for $\mathrm{CH}_{4}$. Observed data are compared against equilibrium. An engineering model, useful for calculations such as reactor design, and based on three global reactions, adequately represents the DR data.

\section{Materials and Methods}

\subsection{Carbon Nanotubes}

The multi-walled carbon nanotubes (Cheap Tubes Inc., Cambridgeport, VT, USA) used were $10-30 \times 10^{-6} \mathrm{~m}$ length by 20-30 $\times 10^{-9} \mathrm{~m}$ outer diameter. Other compounds used in the synthesis (Sigma-Aldrich) were 95\%+ purity. The synthesis strategy begins with CNT functionalization (becoming F-CNTs) with carboxylic acid groups, followed by the addition of Ru.

The $\mathrm{Ru} / \mathrm{CNT}$ synthesis is described in detail elsewhere [22]. The synthesis begins with CNT carboxylation to enhance dispersibility for the subsequent Ru addition. A known mass of CNTs are dispersed into concentrated $\mathrm{H}_{2} \mathrm{SO}_{4}+\mathrm{HNO}_{3}$ (aqueous). The suspension is radiated with microwaves to $413 \mathrm{~K}$ for $1200 \mathrm{~s}$, and then cooled (room temperature). Vacuum filtering $\left(10^{-5} \mathrm{~m}\right.$ pore size) follows, with Milli $\mathrm{Q}$ water washing to $\mathrm{pH} \approx 7$. These F-CNTs are then vacuum-dried at $343 \mathrm{~K}$.

The dried F-CNTs are then dispersed in diethylene glycol by sonication. $\mathrm{A} \mathrm{RuCl}_{3} \cdot \mathrm{nH}_{2} \mathrm{O}$, sodium acetate, and Milli $\mathrm{Q}$ water mixture is added, followed by more sonication. The new dispersion is processed in the microwave reactor at $473 \mathrm{~K}$ for $600 \mathrm{~s}$. It is estimated that a roughly $20 \%$ conversion of the Ru starting material occurs. Upon cooling, the mass is vacuum filtered and ethanol-washed. The $\mathrm{Ru} / \mathrm{CNT}$ are finally vacuum-dried at $343 \mathrm{~K}$ to a constant mass.

\subsection{Catalyst Testing System}

The apparatus used for the $\mathrm{Ru} / \mathrm{CNT}$ catalysis testing is described elsewhere $[23,24]$. The $\mathrm{CH}_{4}$, $\mathrm{CO}_{2}$, and diluent He flow rates were set by calibrated mass flow controllers. Catalyst was uploaded into the fritted metal cup of a $6.35 \times 10^{-3} \mathrm{~m}$ stainless steel Swagelok (Nupro) in-line filter. The stainless steel tube assembly was placed in a 3-zone electric furnace. Results presented elsewhere [23] show that the steel reactor vessel was inert during these DR experiments.

The on-line gas analysis was performed with a model 5890 Hewlett-Packard gas chromatograph/ thermal conductivity detector (GC/TCD) fed through a gas sample loop and valve. The pressure in the reactor flow system was monitored and manually controlled. The operator alternately directed feed (bypass) or reactor effluent to the on-line GC/TCD. 
In this DR research, the inlet $\mathrm{CH}_{4}$ and $\mathrm{CO}_{2}$ were diluted by $85 \% \mathrm{He}$, resulting in approximately constant total molar flow rate. The experimental $\mathrm{CH}_{4}, \mathrm{CO}, \mathrm{CO}_{2}$ mole fractions allowed atomic carbon balances, and estimates of any carbon deposits. These data also facilitated $\mathrm{H}$ and $\mathrm{O}$ balances for $\mathrm{H}_{2}$ and $\mathrm{H}_{2} \mathrm{O}$ concentrations. Where feasible, $\mathrm{H}_{2}$ levels determined this way were verified by the GC/TCD data for $\mathrm{H}_{2}$.

System pressure was kept constant $\left(3.03 \times 10^{5} \mathrm{~Pa}\right.$, abs.). Temperatures studied were 773-973 K, while the molar $\mathrm{CH}_{4} / \mathrm{CO}_{2}$ feed ratio was 0.5-2.0. Most runs were at constant total inlet rate $\left(1.12 \times 10^{-6}\right.$ std. $\left.\mathrm{m}^{3} / \mathrm{s}\right)$. Total catalyst mass was $0.002 \mathrm{~kg}(0.0004 \mathrm{~kg} \mathrm{Ru} / \mathrm{CNTs}, 0.0016 \mathrm{~kg}$ Y-zeolite $)$. The resulting gas space velocity (GSV) was $5.56 \times 10^{-4} \mathrm{~m}^{3} / \mathrm{s}-\mathrm{kg}$. Variable total feed rate experiments were also done at an equimolar feed $\mathrm{CH}_{4}$ and $\mathrm{CO}_{2}$.

\section{Results}

\subsection{Catalyst Characterization}

The $\mathrm{Ru} / \mathrm{CNT}$ was characterized using a scanning electron microscope (SEM, JEM 2800) and a transmission electron microscope (TEM, F2000). Figure 1 (left) shows SEM images of the synthesized $\mathrm{Ru} / \mathrm{CNT}$. After Ru deposition, the CNTs are intact with no apparent damage. Close inspection of the TEM image in Figure 1 (right) reveals Ru nanoparticles. Their approximate particle size range is $1-5 \times 10^{-9} \mathrm{~m}$. Subsequent SEM testing of the catalyst after all the DR runs showed little if any sintering of the Ru.
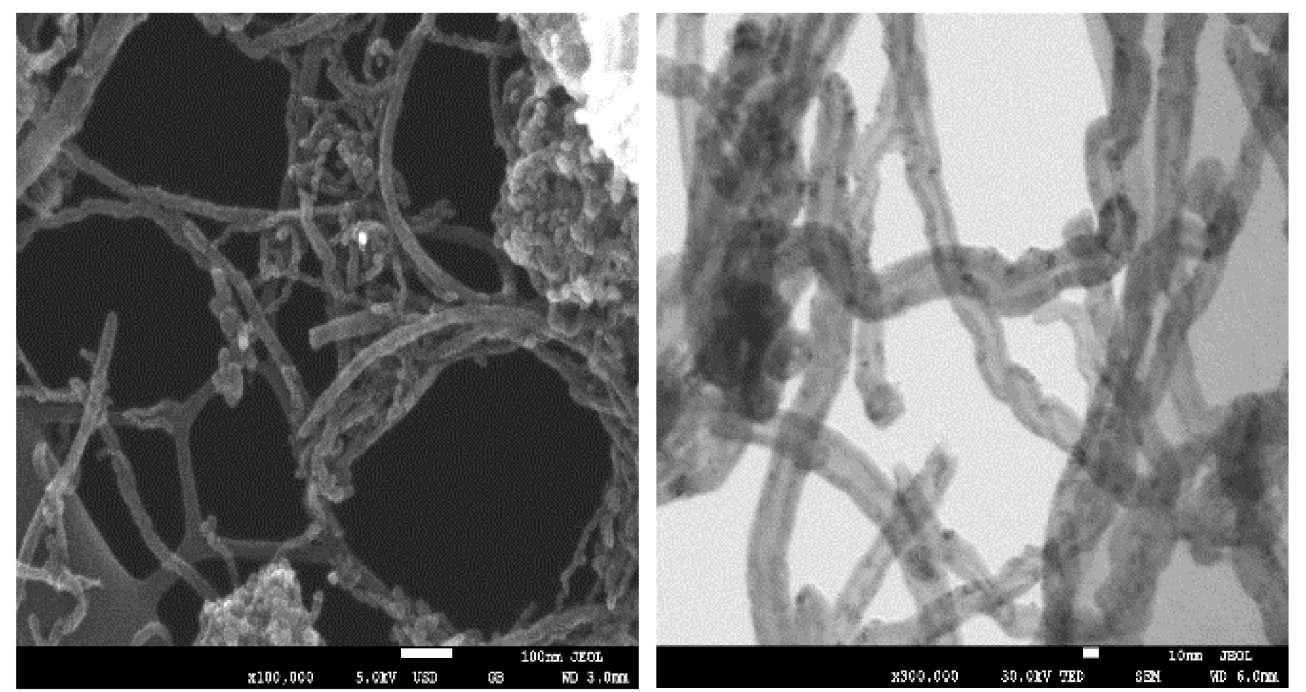

Figure 1. (a) scanning electron microscope (SEM, 100× magnification) and (b) transmission electron microscope (TEM, 300 $\times$ magnification) images of the synthesized ruthenium/carbon nanotube ( $\mathrm{Ru} / \mathrm{CNT})$. The Ru nanoparticles are the very tiny $\left(1-5 \times 10^{-9} \mathrm{~m}\right)$ black spots in the TEM.

The thermogravimetric analysis (TGA, in air) of our Ru/CNTs is shown in Figure 2. Weight loss in the $403-873 \mathrm{~K}$ range is due to $\mathrm{Ru} / \mathrm{CNT}$ decomposition in air. The $10 \%$ remaining mass is likely $\mathrm{RuO}_{2}$. Elemental analysis from energy-dispersive X-ray spectroscopy (EDX) (Table 1) is consistent with this hypothesis. 


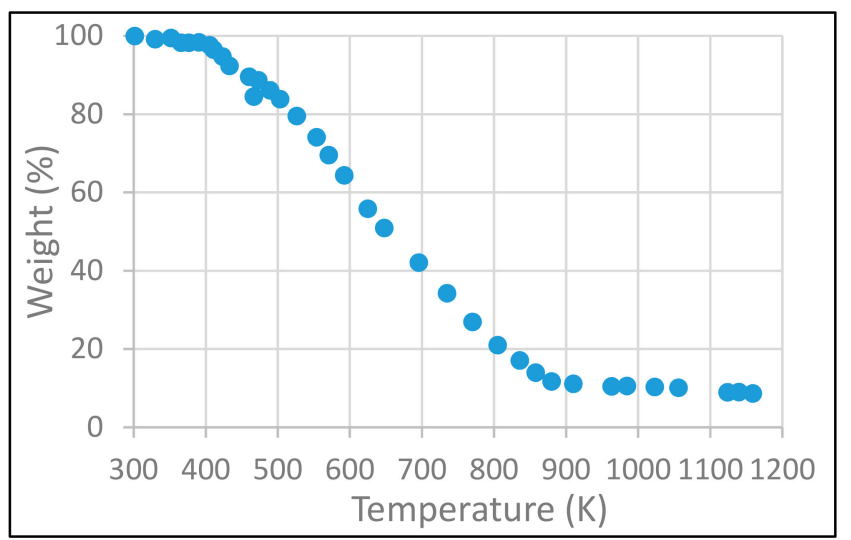

Figure 2. Thermogravimetric analysis (TGA) of Ru/CNT in air.

Table 1. Elemental analysis of samples by energy-dispersive X-ray spectroscopy (EDX).

\begin{tabular}{cccccc}
\hline & $\mathbf{C}$ & $\mathbf{O}$ & $\mathbf{F e}$ & $\mathbf{N i}$ & $\mathbf{R u}$ \\
\hline Raw CNTs & 96.50 & 1.38 & 0.68 & 1.44 & - \\
$\mathrm{Ru} / \mathrm{CNTs}$ & 83.97 & 7.28 & - & - & 8.75 \\
\hline
\end{tabular}

To extend the physical mass of the solids for ease of handling, the $\mathrm{Ru} / \mathrm{CNT}$ were mixed with Y-zeolite of similar particle size. The Y-zeolite was the inert $\mathrm{Na}$ form, used as delivered (Alfa Aesar, Haverhill, MA, USA) with a 5.5:1 molar ratio $\mathrm{SiO}_{2}: \mathrm{Al}_{2} \mathrm{O}_{3}$. The solids mixture was $20 \mathrm{wt} . \% \mathrm{Ru} / \mathrm{CNT}$. Results presented elsewhere [23] show that the added zeolite was effectively inert during our DR experiments. The particles $\left(\sim 3 \times 10^{-5} \mathrm{~m}\right.$ diameter) were small enough to avoid significant external and internal mass transfer resistances (Mears and Weisz-Prater criteria, respectively, as discussed in [23]). Based on CO adsorption and BET surface area tests of the Ru/CNT-zeolite catalyst, the Ru site density was $\sim 9 \times 10^{-8} \mathrm{moles} / \mathrm{m}^{2}[23]$.

\subsection{Modeling}

Modeling begins with reaction equilibrium calculations. Then we propose a three reaction global engineering kinetic model calibrated against experimental data.

\subsubsection{Equilibrium Calculations}

In this study, all experimental runs were tested with the Chemkin-Pro ${ }^{\circledR}$ equilibrium application [25]. The calculation is based on the element-potential method used in Stanjan [26]. The equilibrium composition minimizes total Gibbs Free Energy.

The equilibrium calculation is run with specified temperature (constant), pressure (constant), and feed composition. The allowed equilibrium species are $\mathrm{H}_{2}, \mathrm{H}_{2} \mathrm{O}, \mathrm{CO}, \mathrm{CO}_{2}, \mathrm{CH}_{4}, \mathrm{He}$, and solid carbon (Cs, when allowed-assumed graphite). The Chemkin-Pro database provides the thermodynamic properties of the species.

Table 2 compares the equilibrium simulation results with and without the solid carbon Cs for an experimental case. For a feed where $\mathrm{CH}_{4} / \mathrm{CO}_{2}=1$, the amount of $\mathrm{H}_{2}$ is roughly about the same in the two cases. However, allowing $\mathrm{Cs}$ results in much less equilibrium $\mathrm{CH}_{4}$ and $\mathrm{CO}$. Indeed, $\mathrm{Cs}$ is the second largest quantity species after $\mathrm{H}_{2}$, and the equilibrium $\mathrm{H}_{2} / \mathrm{CO} \geq 1$. Without $\mathrm{Cs}$, equilibrium $\mathrm{H}_{2} / \mathrm{CO}<1$. A similarly large impact of $\mathrm{Cs}$ in equilibrium was reported elsewhere [27]. 
Table 2. Impact of solid carbon (Cs) on equilibrium; $\mathrm{T}=973 \mathrm{~K}, \mathrm{P}=3.03 \times 10^{5} \mathrm{~Pa}$, initial $\mathrm{CH}_{4} / \mathrm{CO}_{2}=1$.

\begin{tabular}{cccc}
\hline Species & Feed (Mole Fractions) & Equil (w/o Cs) (Mole Fracs) & Equil (w/Cs) (Mole Fractions) \\
\hline $\mathrm{CH}_{4}$ & 0.0725 & 0.0227 & 0.0010 \\
$\mathrm{CO}_{2}$ & 0.0725 & 0.0160 & 0.0284 \\
$\mathrm{CO}$ & - & 0.0930 & 0.0253 \\
$\mathrm{H}_{2}$ & - & 0.0796 & 0.0802 \\
$\mathrm{H}_{2} \mathrm{O}$ & - & 0.0067 & 0.0440 \\
$\mathrm{He}$ & 0.8550 & 0.7820 & 0.7497 \\
$\mathrm{Cs}$ & $\mathrm{n} / \mathrm{a}$ & $\mathrm{n} / \mathrm{a}$ & 0.0714 \\
$\mathrm{SUM}$ & 1.0000 & 1.0000 & 1.0000 \\
$\mathrm{H}_{2} / \mathrm{CO}$ & n/a & 0.856 & 3.17 \\
\hline
\end{tabular}

\subsubsection{Global Kinetic Model}

An engineering global kinetic model has the advantage of offering relatively easy calculations for an otherwise complex reaction system. It is not meant to substitute for a detailed elementary reaction mechanism that requires a complex software package such as Chemkin-Pro to evaluate. The global model is a screening tool, and is limited to the region over which it is calibrated.

Analysis began with an experimental carbon balance. Measured feed $\mathrm{CH}_{4}+\mathrm{CO}_{2}$ mole fractions were compared to measured outlet $\mathrm{CH}_{4}+\mathrm{CO}_{2}+\mathrm{CO}$. Heavy He dilution minimized the impact of any changes in total molar rate by reactions. Figure 3 presents a parity plot of the experimental carbon balance. Points below the diagonal suggest carbon deposition occurred during those runs.

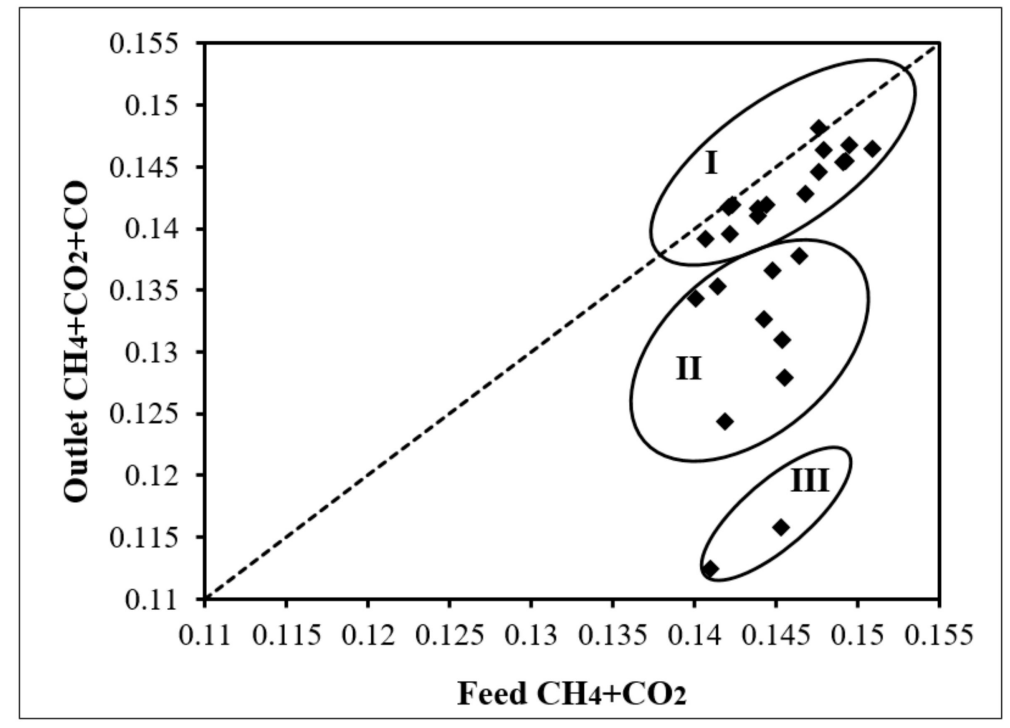

Figure 3. Carbon balance for all runs over Ru/CNT-zeolite. Circle I: 773, 823, 873 K; Circle II: 923, 973 K; Circle III: $973 \mathrm{~K}$ at higher feed $\mathrm{CH}_{4} / \mathrm{CO}_{2}$.

A closer look of the marker distribution in the graphic reveals:

1. Circle I shows the runs at 773,823 , and $873 \mathrm{~K}$. These are very close or even at the parity line suggesting little carbon deposition at these lower temperatures.

2. Circle II and III present the runs at $923 \mathrm{~K}$ and $973 \mathrm{~K}$. Compared to circle I, higher temperature favors coke formation.

3. Circle III shows two cases at $973 \mathrm{~K}$. They are even further from the parity line than the other runs at $973 \mathrm{~K}$ (Circle II, feed $\mathrm{CH}_{4} / \mathrm{CO}_{2}$ range $0.51-1.01$ ) due to higher feed $\mathrm{CH}_{4} / \mathrm{CO}_{2}(1.53,2.08)$. The same observation is obtained at the other temperatures-higher $\mathrm{CH}_{4} / \mathrm{CO}_{2}$ at comparable temperatures favors coke formation.

4. For all runs, the further below the parity line, the higher $\mathrm{H}_{2} / \mathrm{CO}$ is observed. It is implied that the formation of higher $\mathrm{H}_{2}$ is coincident with coke formation. 
In view of Figure 3, our global kinetic model uses the following three reactions:

$$
\begin{aligned}
& \text { Dry Reforming } \quad \mathrm{CH}_{4}+\mathrm{CO}_{2}=2 \mathrm{CO}+2 \mathrm{H}_{2} \\
& \text { Reverse Water Gas Shift } \quad \mathrm{CO}_{2}+\mathrm{H}_{2}=\mathrm{H}_{2} \mathrm{O}+\mathrm{CO} \\
& \text { Methane Decomposition } \quad \mathrm{CH}_{4}=\mathrm{Cs}+2 \mathrm{H}_{2}
\end{aligned}
$$

Equation (1) presents the ideal DR reaction, and is chosen naturally. The reverse water gas shift (RWGS, Equation (2)) occurs during reforming [28]. Reactions 1 and 2 suggest $\mathrm{H}_{2} / \mathrm{CO}<1$, which is coincident with most of our cases. However, numerous runs showed $\mathrm{H}_{2} / \mathrm{CO}>1$ at higher temperatures and feed $\mathrm{CH}_{4} / \mathrm{CO}_{2}$. This might be explained by either the $\mathrm{CH}_{4}$ decomposition (MD, Equation (3)) generating more $\mathrm{H}_{2}$, or Boudouard reaction $\left(2 \mathrm{CO} \rightarrow \mathrm{CO}_{2}+\mathrm{Cs}\right.$ ) consuming more $\mathrm{CO}$. However, higher temperatures favor MD equilibrium but discourage Boudouard. It has been claimed that DR occurs through a catalytic decomposition of $\mathrm{CH}_{4}$ to adsorbed $\mathrm{C}$ and $\mathrm{H}$ atoms, thus facilitating carbon deposits [28]. Finally, Reactions 2 and 3 are known to occur during $\mathrm{CH}_{4}$ DR [21].

The selected reversible reactions for the global model and their rate expressions are summarized in Table 3. If the approach to equilibrium $\eta_{i}>1$, the reaction goes left to right; if $\eta_{i}<1$, the reaction goes in reverse; if $\eta_{i}=1$, the reaction is at equilibrium. The equilibrium constants $K_{p i}$ (Table 3), are regressed vs. temperature from an on-line calculator [29]. For Reactions 1 and 3, the first order $\mathrm{CH}_{4}$ kinetics are suggested elsewhere [28]. The Reaction 2 first-order $\mathrm{CO}_{2}$ kinetics are also suggested elsewhere [30]. A regression strategy was used to estimate the Arrhenius parameter pairs $\left(\mathrm{A}_{\mathrm{i}}, \mathrm{E}_{\mathrm{i}}\right)$, Assuming a packed-bed reactor (PBR) model (Table 4), our DR experiments were simulated. The experimental $\mathrm{CH}_{4}$ and $\mathrm{CO}_{2}$ conversions are sufficiently high $(>10 \%)$ that an integral PBR model is used rather than a simple differential reactor.

Table 3. Global kinetic engineering model with primary dry reforming (DR) and secondary reverse water gas shift (RWGS), methane decomposition (MD) reactions.

\begin{tabular}{cccc}
\hline Reaction & Rate Expression $\mathbf{r}_{\mathbf{i}}$ & Appr. to Equil. $\eta_{\mathbf{i}}$ & $\mathbf{K}_{\mathbf{p i}}$ \\
\hline $\begin{array}{c}\text { Dry Reforming } \\
\mathrm{CH}_{4}+\mathrm{CO}_{2}=2 \mathrm{CO}+2 \mathrm{H}_{2}\end{array}$ & $r_{1}=k_{1} P_{\mathrm{CH} 4} P_{\mathrm{CO} 2}\left(1-\eta_{1}\right)$ & $\eta_{1}=\frac{P_{\mathrm{CO}}^{2} P_{\mathrm{H} 2}^{2}}{P_{\mathrm{CH} 4} P_{\mathrm{CO} 2} K_{p 1}}$ & $\exp \left(-\frac{31234}{T}+34.093\right)$ \\
\hline $\begin{array}{c}\text { Reverse Water Gas Shift } \\
\mathrm{CO}_{2}+\mathrm{H}_{2}=\mathrm{CO}+\mathrm{H}_{2} \mathrm{O}\end{array}$ & $r_{2}=k_{2} P_{\mathrm{CO} 2}\left(1-\eta_{2}\right)$ & $\eta_{2}=\frac{P_{\mathrm{CO}} P_{\mathrm{H} 2 \mathrm{O}}}{P_{\mathrm{H} 2} P_{\mathrm{CO} 2} K_{p 2}}$ & $\exp \left(-\frac{430300}{T^{2}}-\frac{3344.7}{T}+3.3995\right)$ \\
\hline $\begin{array}{c}\text { Methane Decomposition } \\
\mathrm{CH}\end{array}$ & $r_{3}=k_{3} P_{\mathrm{CH} 4}\left(1-\eta_{3}\right)$ & $\eta_{3}=\frac{P_{\mathrm{H} 2}^{2}}{P_{\mathrm{CH} 4} K_{p 3}}$ & $\exp \left(-\frac{10534}{T}+12.851\right)$ \\
\hline
\end{tabular}

Table 4. Key packed-bed reactor (PBR) simulation equations using 3-reaction global model (Table 3).

\begin{tabular}{cccc}
\hline PBR Balances Species $\mathbf{j}$ & Net Rates $\mathbf{r}_{\mathbf{j}}$ & Mole Fractions $\mathbf{y}_{\mathbf{j}}$ & Partial Pressures \\
\hline & $r_{\mathrm{CH} 4}=-r_{1}-r_{3}$ & & \\
$d F_{j} / d W=r_{j}$ & $r_{\mathrm{CO} 2}=-r_{1}-r_{2}$ & $y_{j}=\frac{F_{j}}{\sum_{j} F_{j}}$ & $P_{j}=y_{j} P$ \\
At $\mathrm{W}=0$, & $r_{C O}=2 r_{1}+r_{2}$ & Total molar rate includes & $\mathrm{P}=$ total pressure \\
$\mathrm{F}_{\mathrm{jo}}=$ value & $r_{\mathrm{H} 2}=2 r_{1}-r_{2}+2 r_{3}$ & inert gas & \\
& $r_{\mathrm{H} 2 \mathrm{O}}=r_{2}$ & & \\
\hline
\end{tabular}

An original Matlab program was developed to simultaneously integrate all PBR species balances with the input of all experimental inlet mole fractions and flow rates at a given temperature and pressure, and then to compare the calculated outlet mole fractions with experimental values. The Matlab program repeats the regression process, resulting in optimized rate constants $\mathrm{k}_{\mathrm{i}}$ at that temperature. The optimized rate constants $k_{i}$ at each temperature were correlated (Figure 4) to obtain quality Arrhenius parameters of each reaction (Table 5). 


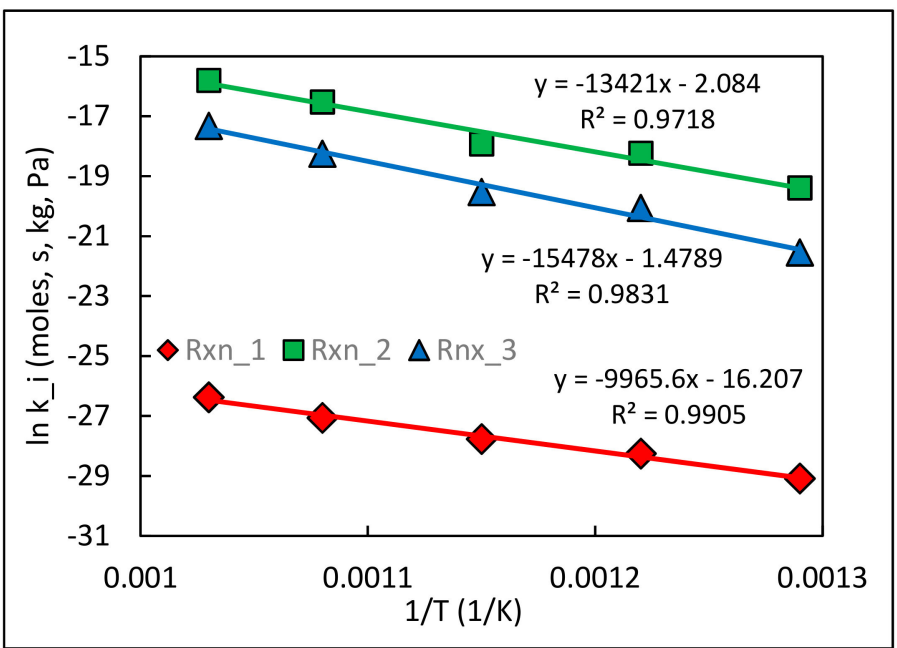

Figure 4. Forward rate constants $k_{i}$ from Table 5 for Reaction (Rxn) 1 (DR), 2 (RWGS), 3 (MD).

Table 5. Arrhenius parameters for Table 3 from Figure 4 analysis; $k_{i}=A_{i} \exp \left[-E_{i} /(R T)\right]$.

\begin{tabular}{ccc}
\hline Reaction $\mathbf{i}$ & Parameter $\mathbf{A}_{\mathbf{i}}$ (mole, s, kg_cat, Pa) & Parameter $\mathbf{E}_{\mathbf{i}} \mathbf{( J / m o l e )}$ \\
\hline 1 & $8.575 \times 10^{-8}$ & 82,446 \\
2 & 0.109 & 110,646 \\
3 & 0.206 & 128,064 \\
\hline
\end{tabular}

A similar analysis method [31] was successfully applied to optimize a 3-global reaction set for methane dehydroaromatization (MDA), inspired elsewhere [32]. In this MDA study, a detailed kinetic mechanism for the surface elementary reactions [33] was evaluated in a PBR model to create a simulated experimental database.

Using the best-fit Arrhenius parameters (Table 5) with the 3-reaction global kinetic set, the experimental DR runs were again simulated, with predicted values compared to the observed. Figure 5 shows example simulated and experimental (outlet) mole fractions at $923 \mathrm{~K}, 3.03 \times 10^{5} \mathrm{~Pa}$, feed $1.12 \times 10^{-6} \mathrm{~m}^{3} / \mathrm{s}$, and feed $\mathrm{CH}_{4} / \mathrm{CO}_{2}=0.5$. Species $\mathrm{H}_{2}$ and $\mathrm{CO}$ rise steadily, while $\mathrm{CO}_{2}$ and $\mathrm{CH}_{4}$ both drop. The experimental outlet mole fractions are well simulated by the global 3-reaction model.

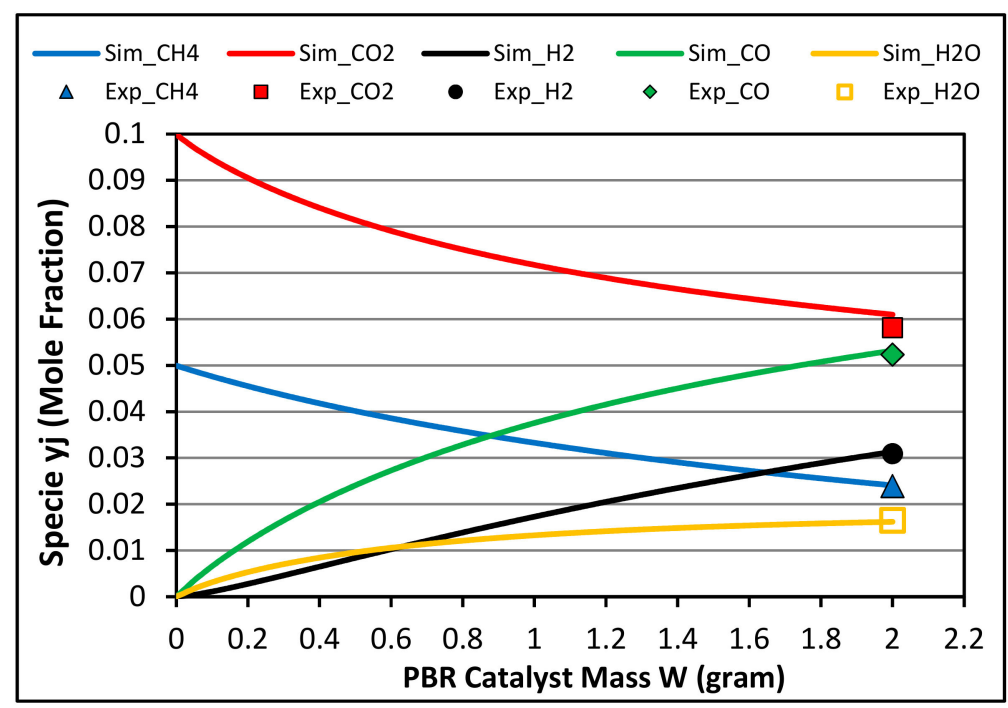

Figure 5. Experimental outlet data, and global model-simulated species PBR profiles: $\mathrm{T}=923 \mathrm{~K}$, feed $\mathrm{CH}_{4} / \mathrm{CO}_{2}=0.5$, gas space velocity $(\mathrm{GSV})=5.56 \times 10^{-4} \mathrm{~m}^{3} / \mathrm{s}-\mathrm{kg}$. “Sim" = model-simulated, "Exp" = experiment. 
Offering further insight, Figure 6 shows model-based $\eta_{i}$ profiles for the Figure 5 case. The DR and MD are far from equilibrium everywhere, while RWGS moves quickly toward equilibrium [28].

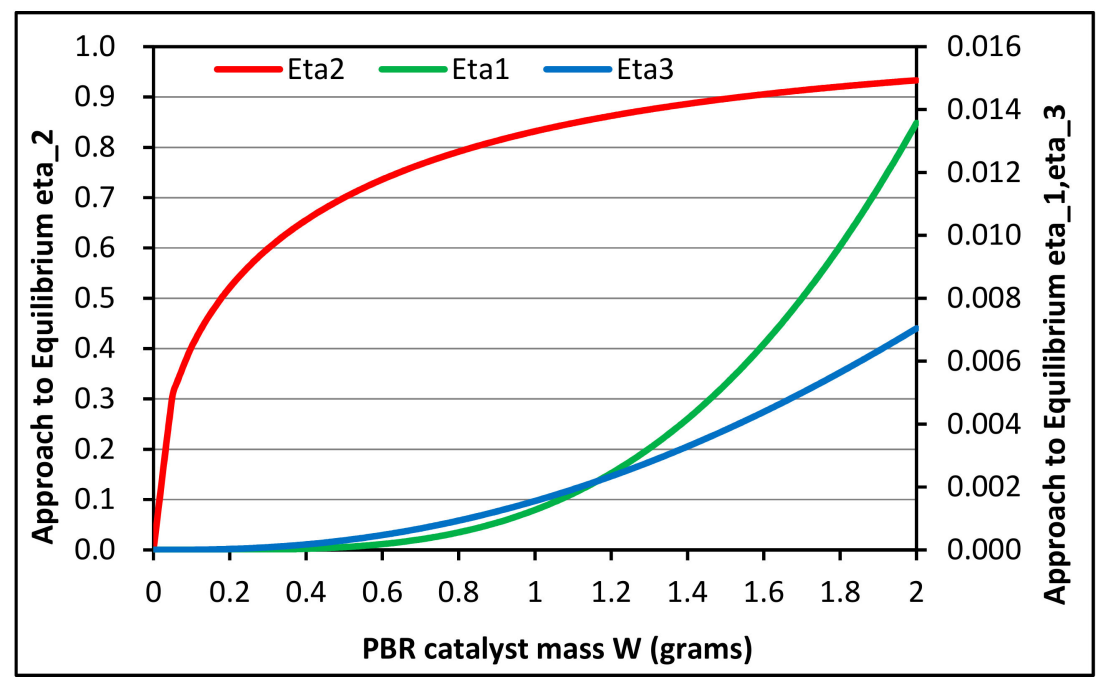

Figure 6. Equilibrium approaches $\left(\eta_{\mathrm{i}}\right)$ : $\mathrm{T}=923 \mathrm{~K}$, feed $\mathrm{CH}_{4} / \mathrm{CO}_{2}=0.5, \mathrm{GSV}=5.56 \times 10^{-4} \mathrm{~m}^{3} / \mathrm{s}-\mathrm{kg}$, corresponding to Figure 5. "Eta i" $=\eta_{i}$ for Reactions 1 (DR), 2 (RWGS), 3 (MD).

\section{Discussion}

The results above illustrate how the 3-reaction global model above was built up based on the observed reactor outlet species concentrations with various experimental temperatures and feed molar $\mathrm{CH}_{4} / \mathrm{CO}_{2}$ ratios. In this section, these results are discussed by demonstrating the utility of the 3-reaction global model by comparison against useful quantities such as reactant conversions and product $\mathrm{H}_{2} / \mathrm{CO}$ ratios. The equilibrium values are also presented in these cases for comparison.

\subsection{Species Concentrations at Reactor Outlet}

For all experimental runs, the $\mathrm{CH}_{4}, \mathrm{CO}_{2}, \mathrm{CO}$ mole fractions were directly measured by GC/TCD. Oxygen atom balances were used, based on measured inlet and effluent $\mathrm{CO}_{2}$ and $\mathrm{CO}$ concentrations, to estimate $\mathrm{H}_{2} \mathrm{O}$. No trace of $\mathrm{O}_{2}$ was detected in any case. Combined with $\mathrm{H}$ atom balance, $\mathrm{H}_{2}$ was estimated using measured inlet and outlet $\mathrm{CH}_{4}$.

To compare the 3-reaction model with experimental results, Figure 7 shows outlet species for all cases at $873 \mathrm{~K}$ at constant feed rate but different feed $\mathrm{CH}_{4} / \mathrm{CO}_{2}$. Figure 8 presents the compositions of all cases at $\mathrm{CH}_{4} / \mathrm{CO}_{2}=1.0$ with constant feed rate as a function of temperature. Acceptable agreements establish the precision of the 3-reaction model. The outlet concentrations of $\mathrm{CO}, \mathrm{H}_{2} \mathrm{O}$, and $\mathrm{H}_{2}$ are significantly impacted by reaction temperature, less so by the inlet $\mathrm{CH}_{4} / \mathrm{CO}_{2}$.

\subsection{Methane and Carbon Dioxide Conversions}

Estimated $\mathrm{CH}_{4}$ and $\mathrm{CO}_{2}$ conversions are based on inlet and outlet mole fractions due to the heavy He dilution. Figure 9 shows variations with temperature of experimental, equilibrium, and 3-reaction model predicted conversions at feed $\mathrm{CH}_{4} / \mathrm{CO}_{2}$ of 2.0 and 0.5 . The 3-reaction model performed very well in predicting observed conversions. 


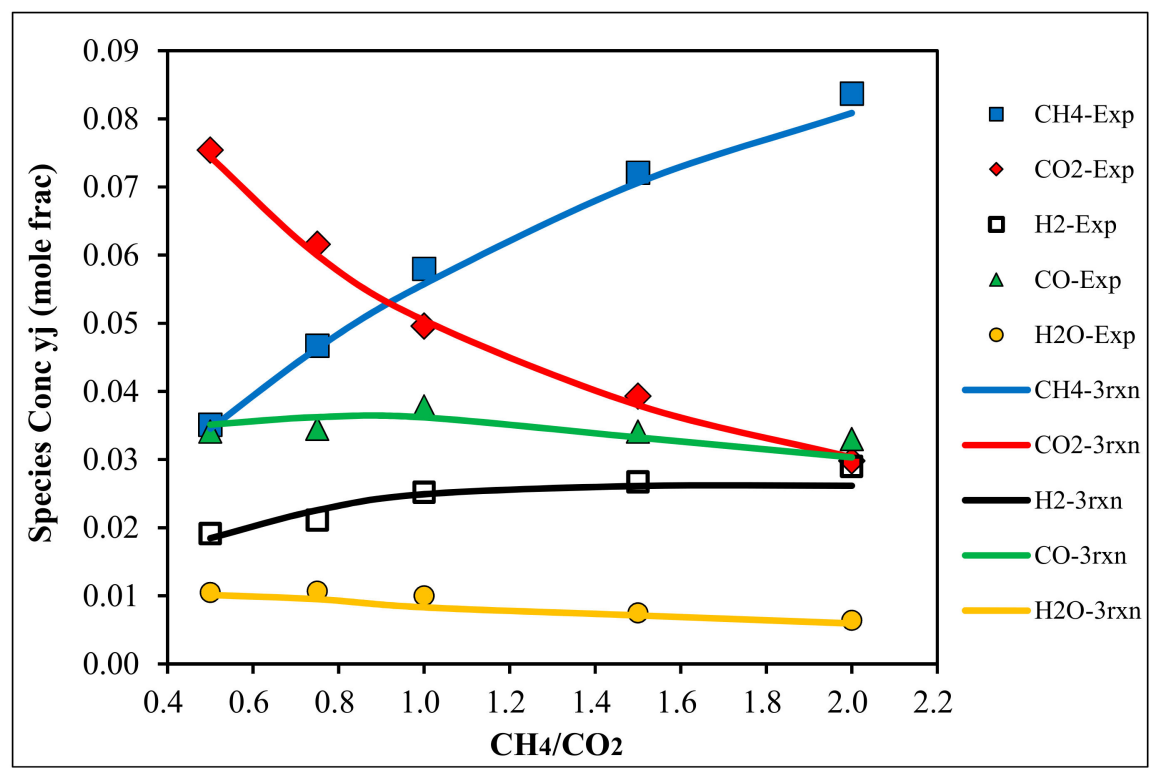

Figure 7. Comparison of experimental and 3-reaction (rxn) model-based outlet concentrations for cases: $873 \mathrm{~K}$ and GSV $=5.56 \times 10^{-4} \mathrm{~m}^{3} / \mathrm{s}-\mathrm{kg}$.

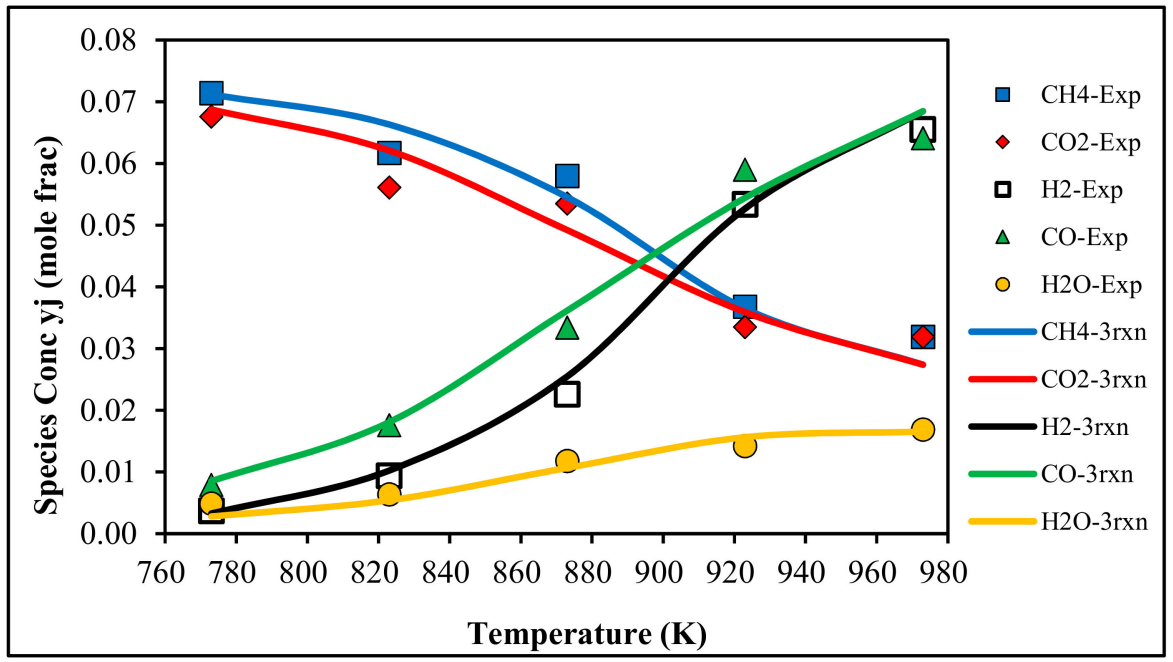

Figure 8. Comparison of experimental and 3-reaction model-based outlet concentrations for cases: $\mathrm{CH}_{4} / \mathrm{CO}_{2}=1.0$ and GSV $=5.56 \times 10^{-4} \mathrm{~m}^{3} / \mathrm{s}-\mathrm{kg}$.

The $\mathrm{CH}_{4}$ equilibrium conversions are much greater than in the experiment, and are insensitive to temperature, suggesting a kinetic potential to improve conversions. Other experimental temperature runs showed similarly consistent results. Figure 10 shows similar results with variation of feed $\mathrm{CH}_{4} / \mathrm{CO}_{2}$. At $973 \mathrm{~K}$, experimental $\mathrm{CO}_{2}$ conversions are much closer to equilibrium, suggesting that $973 \mathrm{~K}$ is nearly the upper temperature limit for improving $\mathrm{CO}_{2}$ conversions with this catalyst.

\subsection{Syngas Molar Ratio $\mathrm{H}_{2} / \mathrm{CO}$}

As a high syngas $\mathrm{H}_{2} / \mathrm{CO}$ ratio is often preferred for many processes, the product mole fraction ratio $\mathrm{H}_{2} / \mathrm{CO}$ is an important index of reforming catalyst effectiveness [34]. Figure 11 shows that higher temperatures and feed $\mathrm{CH}_{4} / \mathrm{CO}_{2}$ favor higher $\mathrm{H}_{2} / \mathrm{CO}$. The 3-reaction global model simulates well the experimental values. At both 773 and $973 \mathrm{~K}$, equilibrium ratios far exceed the observed values. 

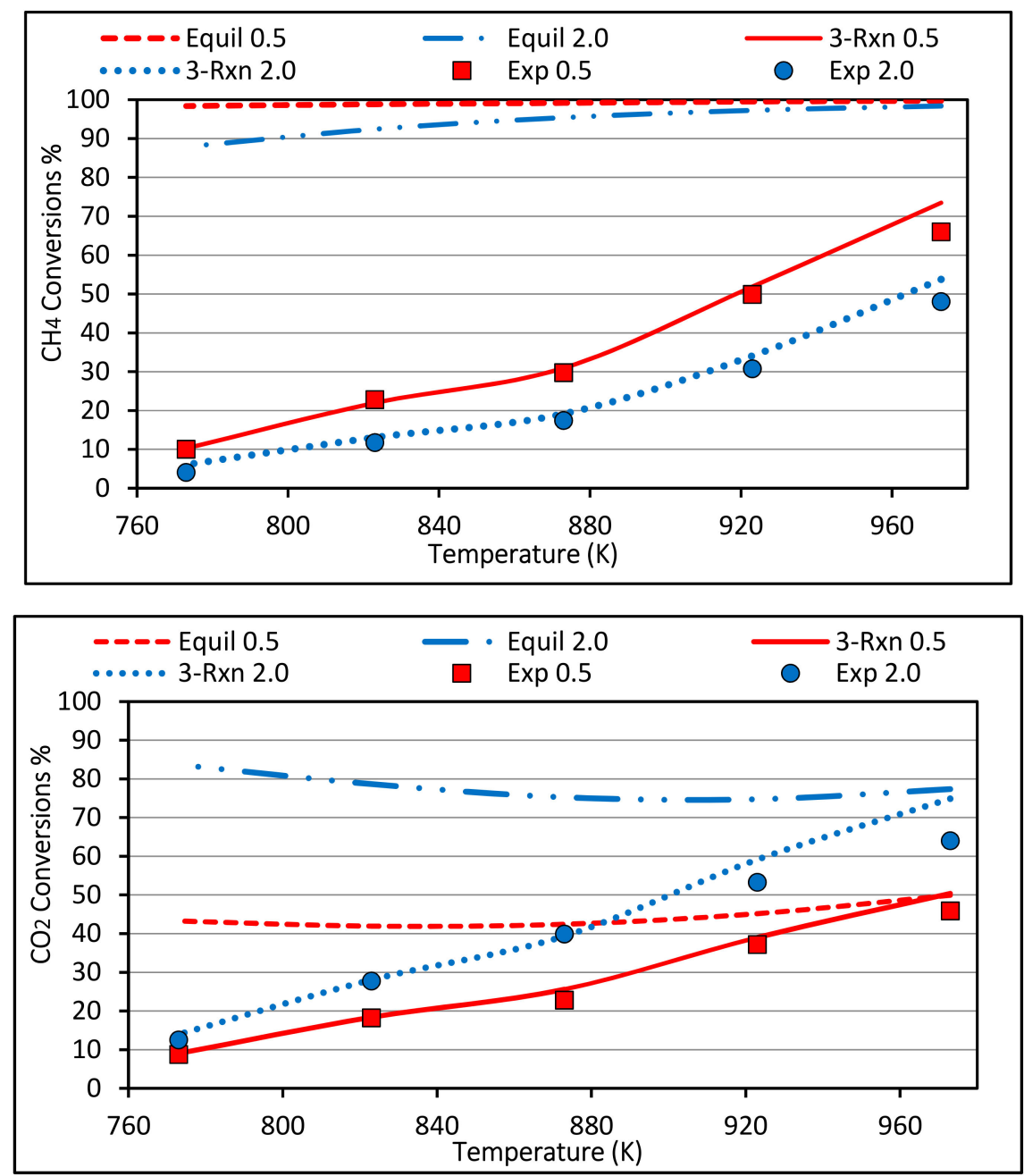

Figure 9. Impact of temperature on $\mathrm{CH}_{4}$ (upper plot) and $\mathrm{CO}_{2}$ (lower plot) conversions at $\mathrm{GSV}=5.56 \times 10^{-4} \mathrm{~m}^{3} / \mathrm{s}-\mathrm{kg}$; feed $\mathrm{CH}_{4} / \mathrm{CO}_{2}=0.5$, 2.0. "Exp" = experiment; "Equil” = equilibrium

The stoichiometric $\mathrm{H}_{2} / \mathrm{CO}$ for the ideal DR reaction is 1.0. At $773 \mathrm{~K}$, the observed $\mathrm{H}_{2} / \mathrm{CO}$ at feed $\mathrm{CH}_{4} / \mathrm{CO}_{2}=1$ is $<1$. This is attributed to the RWGS reaction, which is more thermodynamically favored at these relatively low temperatures [35]. At $973 \mathrm{~K}$ with $\mathrm{CH}_{4} / \mathrm{CO}_{2}=1$, the experimental $\mathrm{H}_{2} / \mathrm{CO}$ is $\approx 1.0$.

\subsection{Comparison of Ru/CNT to Pt_Pd/CNT}

A study similar to the one presented here was performed earlier with Pt_Pd/CNT catalyst, also admixed with inert zeolite [24]. Both the $\mathrm{Ru} / \mathrm{CNT}$ and $\mathrm{Pt} \_\mathrm{Pd} / \mathrm{CNT}$ catalysts were prepared in very similar ways. Based on CO adsorption and BET surface area tests of the metal/CNT-zeolite catalysts, the Pt_Pd and Ru catalyst site densities were estimated as $1.3 \times 10^{-7}$ and $9.0 \times 10^{-8} \mathrm{~mole} / \mathrm{m}^{2}$, respectively [23]. 

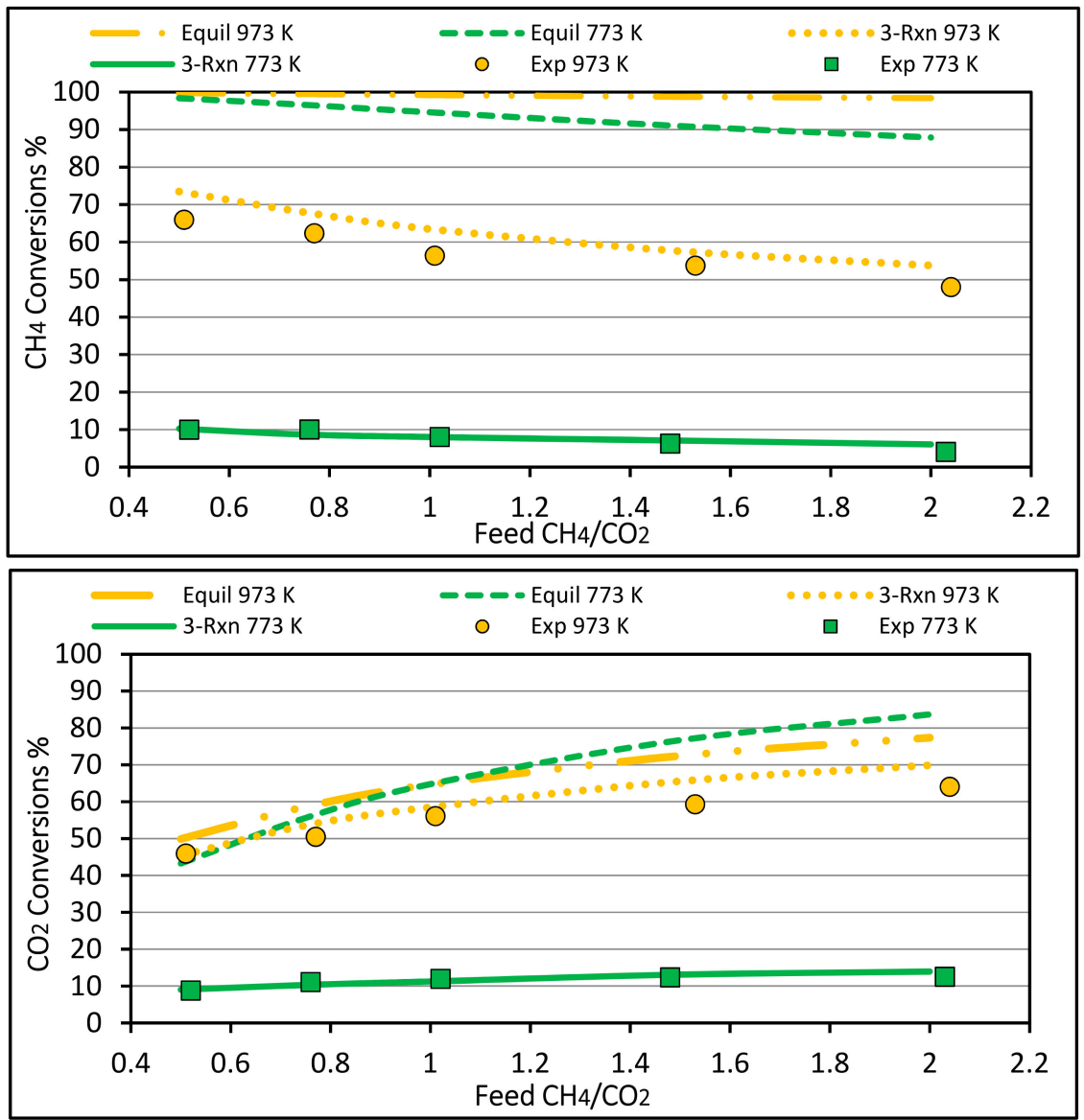

Figure 10. Impact of feed $\mathrm{CH}_{4} / \mathrm{CO}_{2}$ on conversion of $\mathrm{CH}_{4}$ and $\mathrm{CO}_{2}$ at $\mathrm{GSV}=5.56 \times 10^{-4} \mathrm{~m}^{3} / \mathrm{s}-\mathrm{kg}$.

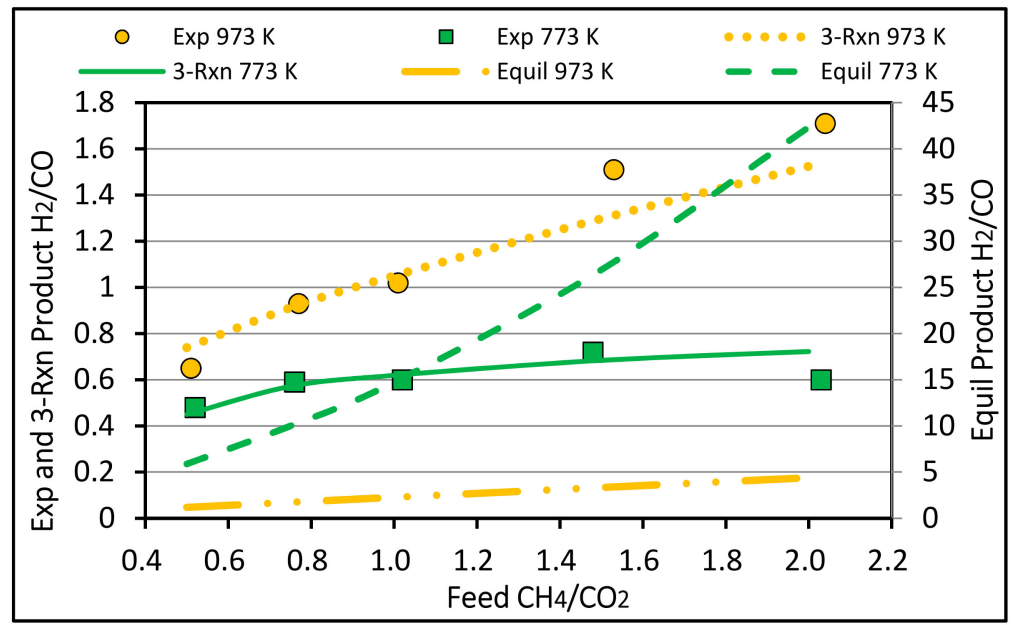

Figure 11. Effect of temperature, feed molar ratio on $\mathrm{H}_{2} / \mathrm{CO}$ at GSV $=5.56 \times 10^{-4} \mathrm{~m}^{3} / \mathrm{s}-\mathrm{kg}$.

Table 6 presents calculated results from the 3-reaction (DR, RWGS, MD) engineering kinetic models presented in this paper for $\mathrm{Ru}$, and in [24] for $\mathrm{Pt}$ _Pd. Each simulation was run with a hypothetical packed-bed reactor with 1 gram of metal/CNT-zeolite catalyst held at a constant $773 \mathrm{~K}, 3.03 \times 10^{5} \mathrm{~Pa}$ pressure, feeding $\mathrm{CH}_{4}$ and $\mathrm{CO}_{2}$ at $5.6 \times 10^{-5} \mathrm{~mole} / \mathrm{s}$ total rate (equimolar). While the differences are fairly small, there is a definite trend that the $\mathrm{Ru} / \mathrm{CNT}$ catalyst, even with a smaller site density, produces a synthesis gas richer in $\mathrm{H}_{2}$. The drawback is a slightly larger Cs. 
Table 6. Comparison of performances from Ru/CNT (model, this study) and Pt_Pd/CNT (model from [21]). $\mathrm{T}=773 \mathrm{~K}, \mathrm{P}=3.03 \times 10^{5} \mathrm{~Pa}, 0.001 \mathrm{~kg}$ catalyst, total feed $5.6 \times 10^{-5} \mathrm{~mole} / \mathrm{s}$, feed $\mathrm{CH}_{4} / \mathrm{CO}_{2}=1$.

\begin{tabular}{cccccccccc}
\hline & $\mathbf{X}_{\mathbf{C H} 4}$ & $\mathbf{X}_{\mathbf{C O} 2}$ & $\mathbf{Y}_{\mathbf{C O}}$ & $\mathbf{Y}_{\mathbf{H} 2}$ & $\mathbf{Y}_{\mathrm{Cs}}$ & $\mathbf{S}_{\mathbf{C O}}$ & $\mathbf{S}_{\mathbf{H} 2}$ & $\mathbf{S}_{\mathrm{Cs}}$ & $\mathbf{H}_{2} / \mathbf{C O}$ \\
\hline $\mathrm{Ru} / \mathrm{CNT}$ & 0.084 & 0.099 & 0.180 & 0.076 & 0.0021 & 2.148 & 0.901 & 0.0255 & 0.838 \\
$\mathrm{Pt} \_\mathrm{Pd} / \mathrm{CNT}$ & 0.075 & 0.091 & 0.164 & 0.066 & 0.0016 & 2.201 & 0.879 & 0.0213 & 0.798 \\
\hline
\end{tabular}

\section{Conclusions}

An Ru catalyst supported on CNT, prepared by a novel microwave synthesis technique, was tested for activity on dry reforming (DR) of $\mathrm{CH}_{4}$ to synthesis gas. The DR studies were undertaken in an isothermal packed bed reactor. The catalyst showed impressive activity and stability at modest temperatures. The outlet species concentrations and conversions were influenced by temperature and feed molar ratio of $\mathrm{CH}_{4} / \mathrm{CO}_{2}$. Based on the analysis of the experiment data, a small amount of carbon deposition was observed during DR, and it was enhanced by higher temperatures and feed $\mathrm{CH}_{4} / \mathrm{CO}_{2}$. Reactant conversions did not reach equilibrium values, suggesting potential to improve conversions and product yield. In order to account for both observed reactant conversions and product species concentrations, a global engineering model consisting of three reversible reactions was developed. The model reactions are dry reforming (ideal), reverse water gas shift, and methane decomposition. The three-reaction model adequately represents the observed species profiles as functions of temperature $(773-973 \mathrm{~K})$ and feed $\mathrm{CH}_{4} / \mathrm{CO}_{2}(0.5-2.0)$. Linear Arrhenius plots for the forward rate constants are observed for each reaction in the model over the calibration temperature range. The calibrated engineering model for the $\mathrm{Ru} / \mathrm{CNT}$ catalyst predicts a higher selectivity and yield for $\mathrm{H}_{2}$ in comparison to previously published results for a similarly prepared $\mathrm{Pt} \_\mathrm{Pd} / \mathrm{CNT}$ catalyst from our group, although at the expense of slightly more carbon deposits.

Author Contributions: Catalyst preparation and characterization: K.C.; Kinetic data collection and analyses: Y.Z.; Software preparation for data analysis: Y.Z.; Experiment simulations: Y.Z.; Writing-Original Draft Preparation, Y.Z.; Writing—Review and Editing: R.B., S.M.; Project Supervision: S.M., R.B.; Funding Acquisition: S.M. All authors have read and agreed to the published version of the manuscript.

Funding: This work was supported by the National Institute of Environmental Health Sciences (NIEHS) under Grant No. R01ES023209. Any opinions, findings, and conclusions or recommendations expressed in this material are those of the author(s) and do not necessarily reflect the views of the NIEHS.

Acknowledgments: The authors appreciate support from their respective departments, as well as a Faculty Instrument Usage Grant from the NJIT Material Characterization Laboratory.

Conflicts of Interest: None of the authors have any conflicts of interest regarding the work presented here.

\section{References}

1. Kanellos, M. The Mind-Boggling Statistics around Wasted Natural Gas. Forbes. Available online: http://www.forbes.com/sites/michaelkanellos/2015/01/29/the-mind-boggling-statistics-aroundwasted-natural-gas/\#14587d1a7e18 (accessed on 29 January 2015).

2. Nunez, C. Oil Drillers' Burning of Natural Gas Costs U.S. Millions in Revenue. In National Geographic; National Geographic Partners: Washington, DC, USA, 2014.

3. Yang, S.; Dezember, R. The U.S. is overflowing with Natural Gas. Not Everyone Can Get It. Wall Street Journal, 8 July 2019.

4. Harder, A. EPA to Propose Rules Cutting Methane Emissions from Oil and Gas Drilling. Wall Street Journal, 17 August 2015.

5. Elrod, M.J. Greenhouse Warming Potentials from the Infrared Spectroscopy of Atmospheric Gases. J. Chem. Educ. 1999, 76, 1702. [CrossRef]

6. Usman, M.; Daud, W.W.; Abbas, H.F. Dry reforming of methane: Influence of process parameters-A review. Renew. Sustain. Energy Rev. 2015, 45, 710-744. [CrossRef] 
7. Ma, Q.; Wang, D.; Wu, M.; Zhao, T.; Yoneyama, Y.; Tsubaki, N. Effect of catalytic site position: Nickel nanocatalyst selectively loaded inside or outside carbon nanotubes for methane dry reforming. Fuel 2013, 108, 430-438. [CrossRef]

8. Qu, Y.; Sutherland, A.M.; Guo, T. Carbon Dioxide Reforming of Methane by Ni/Co Nanoparticle Catalysts Immobilized on Single-Walled Carbon Nanotubes. Energy Fuels 2008, 22, 2183-2187. [CrossRef]

9. Wu, T.; Zhang, Q.; Cai, W.; Zhang, P.; Song, X.; Sun, Z.; Gao, L. Phyllosilicate evolved hierarchical Ni- and $\mathrm{Cu}-\mathrm{Ni} / \mathrm{SiO} 2$ nanocomposites for methane dry reforming catalysis. Appl. Catal. A Gen. 2015, 503, 94-102. [CrossRef]

10. Drif, A.; Bion, N.; Brahmi, R.; Ojala, S.; Pirault-Roy, L.; Turpeinen, E.; Seelam, P.K.; Keiski, R.L.; Epron, F. Study of the dry reforming of methane and ethanol using Rh catalysts supported on doped alumina. Appl. Catal. A Gen. 2015, 504, 576-584. [CrossRef]

11. Hinkley, J.; Agrafiotis, C. Solar Thermal Energy and its Conversion to Solar Fuels via Thermochemical Processes. In Chapter 9, Polygeneration with Polystorage for Chemical and Energy Hubs for Energy and Chemicals; Khalilpour, K.R., Ed.; Academic Press: Cambridge, MA, USA, 2019; pp. 247-286.

12. Park, J.-H.; Yeo, S.; Chang, T.S. Effect of supports on the performance of Co-based catalysts in methane dry reforming. J. CO2 Util. 2018, 26, 465-475. [CrossRef]

13. Zhang, J.; Li, F. Coke-resistant $\mathrm{Ni} @ S i O_{2}$ catalyst for dry reforming of methane. Appl. Catal. B Environ. 2015, 176, 513-521. [CrossRef]

14. Yamagishi, T.; Furikado, I.; Ito, S.; Miyao, T.; Naito, S.; Tomishige, K.; Kunimori, K. Catalytic Performance and Characterization of $\mathrm{RhVO} 4 / \mathrm{SiO} 2$ for Hydroformylation and $\mathrm{CO}$ Hydrogenation. J. Mol. Catal. A Chem. 2006, 244, 201-212. [CrossRef]

15. Giehr, A.; Maier, L.; Schunk, S.A.; Deutschmann, O. Thermodynamic Considerations on the Oxidation State of $\mathrm{Co} / \gamma-\mathrm{Al}_{2} \mathrm{O}_{3}$ and $\mathrm{Ni} / \gamma-\mathrm{Al}_{2} \mathrm{O}_{3}$ Catalysts under Dry and Steam Reforming Conditions. ChemCatChem 2018, 10, 751-757. [CrossRef]

16. Song, Y.; Ozdemir, E.; Ramesh, S.; Adishev, A.; Subramanian, S.; Harale, A.; AlBuali, M.; Fadhel, B.A.; Jamal, A.; Moon, D.; et al. Dry reforming of methane by stable Ni-Mo nanocatalysts on single-crystalline MgO. Science 2020, 367, 777-781. [CrossRef] [PubMed]

17. Tomishige, K.; Asadullah, M.; Kunimori, K. Syngas Production by Biomass Gasification Using $\mathrm{Rh} / \mathrm{CeO} 2 / \mathrm{SiO}_{2}$ Catalysts and Fluidized Bed Reactor. Catal. Today 2004, 89, 389-403. [CrossRef]

18. Iijima, S. Helical microtubules of graphitic carbon. Nature 1991, 354, 56-58. [CrossRef]

19. Fu, X.; Yu, H.; Peng, F.; Wang, H.; Qian, Y. Facile Preparation of RuO2 /CNT Catalyst by a Homogeneous Oxidation Precipitation Method and Its Catalytic Performance. Appl. Catal. A Gen. 2007, 321, 190-197. [CrossRef]

20. Donphai, W.; Faungnawakij, K.; Chareonpanich, M.; Limtrakul, J. Effect of Ni-CNTs/mesocellular silica composite catalysts on carbon dioxide reforming of methane. Appl. Catal. A Gen. 2014, 475, 16-26. [CrossRef]

21. Khavarian, M.; Chai, S.-P.; Mohamed, A.R. The effects of process parameters on carbon dioxide reforming of methane over Co-Mo-MgO/MWCNTs nanocomposite catalysts. Fuel 2015, 158, 129-138. [CrossRef]

22. Kim, J.-Y.; Kim, K.-H.; Park, S.-H.; Kim, K.-B. Microwave-polyol synthesis of nanocrystalline ruthenium oxide nanoparticles on carbon nanotubes for electrochemical capacitors. Electrochim. Acta 2010, 55, 8056-8061. [CrossRef]

23. Zhu, $\mathrm{Y} . \mathrm{CO}_{2}$ Reduction over Nobel Metal/Carbon Nanotube Catalyst. Ph.D. Thesis, Chemical Engineering Department, New Jersey Institute of Technology, Newark, NJ, USA, 2017.

24. Zhu, Y.; Chen, K.; Yi, C.; Mitra, S.; Barat, R. Dry reforming of methane over palladium-platinum on carbon nanotube catalyst. Chem. Eng. Commun. 2018, 205, 888-896. [CrossRef]

25. Chemkin-Pro Version 15131. Reaction Design, San Diego. Available online: http://www.ansys.com/products/ fluids/ansys-chemkin-pro (accessed on 1 March 2017).

26. Reynolds, W.C. The Element Potential Method for Chemical Equilibrium Analysis: Implementation in the Interactive Program STANJAN; Department of Mechanical Engineering, Stanford University: Stanford, CA, USA, 1986.

27. Pakhare, D.; Spivey, J.J. A review of dry $\left(\mathrm{CO}_{2}\right)$ reforming of methane over noble metal catalysts. Chem. Soc. Rev. 2014, 43, 7813-7837. [CrossRef] [PubMed]

28. Wei, J.; Iglesia, E. Mechanism and Site Requirements for Activation and Chemical Conversion of Methane on Supported Pt Clusters and Turnover Rate Comparisons among Noble Metals. J. Phys. Chem. B 2004, 108, 4094-4103. [CrossRef] 
29. Bale, C.; Belisle, E. Reaction Web. Available online: http://www.crct.polymtl.ca/reacweb.htm (accessed on 1 June 2016).

30. Foppa, L.; Silaghi, M.-C.; Larmier, K.; Comas-Vives, A. Intrinsic reactivity of Ni, Pd and Pt surfaces in dry reforming and competitive reactions: Insights from first principles calculations and microkinetic modeling simulations. J. Catal. 2016, 343, 196-207. [CrossRef]

31. Zhu, Y.; Al-Ebbinni, N.; Henney, R.; Yi, C.; Barat, R. Extension to multiple temperatures of a three-reaction global kinetic model for methane dehydroaromatization. Chem. Eng. Sci. 2018, 177, 132-138. [CrossRef]

32. Li, L.; Borry, R.W.; Iglesia, E. Design and optimization of catalysts and membrane reactors for the non-oxidative conversion of methane. Chem. Eng. Sci. 2002, 57, 4595-4604. [CrossRef]

33. Karakaya, C.; Morejudo, S.H.; Zhu, H.; Kee, R.J. Catalytic Chemistry for Methane Dehydroaromatization (MDA) on a Bifunctional Mo/HZSM-5 Catalyst in a Packed Bed. Ind. Eng. Chem. Res. 2016, 55, 9895-9906. [CrossRef]

34. Bartholomew, C.H.; Farrauto, R.J. Industrial Catalysis Processes; John Wiley \& Sons, Inc.: Hoboken, NJ, USA, 2005.

35. Quiroga, M.M.B.; Luna, A.E.C. Kinetic Analysis of Rate Data for Dry Reforming of Methane. Ind. Eng. Chem. Res. 2007, 46, 5265-5270. [CrossRef]

(C) 2020 by the authors. Licensee MDPI, Basel, Switzerland. This article is an open access article distributed under the terms and conditions of the Creative Commons Attribution (CC BY) license (http://creativecommons.org/licenses/by/4.0/). 